\title{
Conjugated and unconjugated oestrogens in fetal and maternal fluids of the cow throughout pregnancy
}

\author{
H. A. Robertson and G. J. King \\ Reproductive Physiology Program, Animal Research Institute, Ottawa, Ontario, Canada K1A \\ OC6 and Department of Animal and Poultry Science, University of Guelph, Guelph, Ontario, \\ Canada N1G $2 W 1$
}

\begin{abstract}
Summary. The changes in concentration of oestrone, oestradiol $(-17 \alpha$ and $-17 \beta)$, oestrone sulphate and the oestradiol sulphates have been measured in allantoic and amniotic fluids and in maternal peripheral plasma throughout gestation. Oestrone sulphate was the major oestrone present in all of the fluids. It was measurable in allantoic fluid before Day 52 and reached a peak concentration of $475 \mathrm{ng} / \mathrm{ml}$ around Day 133. A lower peak occurred in the amniotic fluid around Day 110. The changes in oestradiol sulphates in allantoic fluid were similar to those of oestrone sulphate but at a much lower level. Considerable fluctuation was observed in the oestradiol sulphate concentrations in amniotic fluid. The ratio of oestradiol-17 $\alpha$ sulphate to oestradiol- $17 \beta$ sulphate was considerably higher in amniotic fluid than in allantoic fluid. Consistent changes in the levels of oestrone and the oestradiols were found in amniotic fluid but not in allantoic fluid during the second half of pregnancy. In maternal peripheral plasma oestrone sulphate was measurable before Day 72 . In the limited number of samples analysed no difference in oestrogen concentration due to the sex of the fetus was evident in any of the fetal or maternal fluids.
\end{abstract}

\section{Introduction}

As part of a comparative study on the role of oestrogens synthesized by the conceptus early in pregnancy in the cow, ewe and sow, Robertson \& King (1975) and Robertson, King \& Carnegie (1976) have reported that the concentration of oestrone sulphate increased in the chorioallantoic fluid of the pregnant cow during the 2 nd month of gestation. Similar observations have been made for the chorioallantoic fluid of the sheep (Carnegie \& Robertson, 1978) and the peripheral plasma of the pregnant sow (Robertson \& King, 1974; Robertson, King \& Dyck, 1978). As it is well established that steroid hormones influence the development and maturation of the fetus during intrauterine life (Jost, 1969, 1970; Gorski, 1971) and, later, the induction of parturition (Liggins, 1969), it was considered expedient to extend our investigations on the concentrations of oestrogens in fetal and maternal fluids of the pregnant cow to cover the complete period of pregnancy. The only work so far reported on oestrogens in fetal fluids of the cow is that of Challis et al. (1974) on unconjugated oestrogens in the serum of the fetal calf.

\section{Materials and Methods}

\section{Animals}

Heparinized samples of maternal blood were collected at the time of commercial slaughter from 22 Holstein-Friesian and cross-bred Friesian dairy cows covering a gestation age of Days 72-270. The samples were immediately chilled in ice-cold water and centrifuged within $4 \mathrm{~h}$ of collection. The plasma was transferred in $3 \mathrm{ml}$ aliquots to stoppered glass vials, frozen over solid $\mathrm{CO}_{2}$ and stored at $-20^{\circ} \mathrm{C}$ until assayed. The uterus was removed within $20 \mathrm{~min}$ of death and the 
conceptus exposed by carefully dissecting through the uterus along the mesometrial surface, taking care not to rupture the chorioallantois. Samples of allantoic fluid were aspirated with a minimum of contamination using sterile syringes fitted with 18-gauge needles. In some instances the presence of a transparent gelatinous mass in the allantoic sac made it difficult to obtain samples. The chorioallantois was then ruptured to drain off excess allantoic fluid and to expose the amniotic sac. Amniotic fluid samples were collected in a manner similar to that for allantoic fluid. The fluids were frozen over solid $\mathrm{CO}_{2}$ in $3 \mathrm{ml}$ aliquots in stoppered glass vials and stored at $-20^{\circ} \mathrm{C}$ until assayed.

The fetuses were removed, their sex determined, and the crown-rump length measured. The approximate gestational ages were then determined using the tables compiled by Roberts (1956). For the period between Days 32 and 68, maternal and fetal samples were obtained in a similar manner from 4 Friesian dairy cows of known gestational age (Day $0=$ day of insemination).

\section{Oestrogen assay}

The rabbit anti-oestrogen serum (courtesy of Dr B. V. Caldwell) used in the assays crossreacts as follows: oestradiol-17 $1,100 \%$; oestradiol- $17 \alpha, 30 \%$; oestrone, $60 \%$. All the standard curves were prepared by the displacement of $\left[{ }^{3} \mathrm{H}\right]$ oestradiol- $17 \beta$. The cross-reactivity with oestradiol-17 $\alpha$ was only $30 \%$ of that with oestradiol- $17 \beta$ and since the total oestradiol values were determined using an oestradiol-17 $\beta$ standard curve the total oestradiol concentrations would be underestimated if a significant amount of oestradiol-17 $\alpha$ were present. The volume of fluid analysed ranged from 0.5 to $2 \mathrm{ml}$ depending upon the concentration present. All assays were carried out in duplicate and have been corrected for individual procedural losses by

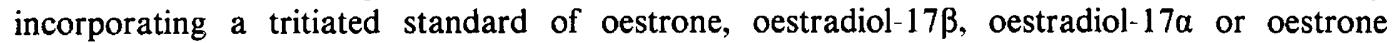
sulphate.

Unconjugated oestrogens. Uniconjugated oestrone, oestradiol-17 $\beta$ and oestradiol-17 $\alpha$ were determined as described by Abraham, Tulchinsky \& Korenman (1970), Robertson, Smeaton \& Durnford (1972) and Carnegie \& Robertson (1978). The mean recoveries and sensitivities were $80 \%$ and $15 \mathrm{pg} /$ tube for oestrone and $68 \%$ and $12 \mathrm{pg} /$ tube for oestradiol.

Oestrogen sulphates. Following benzene extraction of the unconjugated oestrogens, conjugated oestrogens in the form of oestrogen sulphates were assayed in both plasma and fetal fluids using the method of Loriaux, Ruder \& Lipsett (1971) as modified by Robertson \& King (1974) and Carnegie \& Robertson (1978). The sensitivity was $40 \mathrm{pg}$ for oestrone sulphate, expressed as the unconjugated oestrone equivalent, and about $45 \mathrm{pg}$ for oestradiol sulphate. It was not established whether the oestradiol sulpho-conjugates were present as the 3 or 17 -monosulphates and/or 3,17-disulphates. If they arise from the reduction of oestrone sulphate then the sulphate group will occupy the 3 position. In a selected series of samples oestradiol-17 $\beta$ sulphate and oestradiol-17 $\alpha$ sulphate were separated after solvolysis by subjecting the mixture to a selective oxidative procedure using the specificity, under certain conditions (Robertson et al., 1972 ), of a 17 $\beta$-hydroxysteroid dehydrogenase preparation which converted oestradiol-17 $\beta$ to oestrone leaving the majority (98\%) of the oestradiol-17 $\alpha$ unchanged. Oestrone and oestradiol$17 \beta$ were then separated on celite columns, assayed and the results expressed in terms of oestradiol $17 \beta$ and oestradiol- $17 \alpha$.

\section{Results}

For ease of comparison of data, the oestrogen sulphate concentrations have been expressed as the unconjugated oestrogen equivalent. To correct for the actual gravimetric amounts of oestrone sulphate and of oestradiol sulphate (as monosulphate) the values should be multiplied by 1.4 . 
Table 1. The concentration of oestrone sulphate (expressed as oestrone) in allantoic and amniotic fluids of the cow during early pregnancy

\begin{tabular}{ccc}
\hline & \multicolumn{2}{c}{ Oestrone sulphate (pg/ml) } \\
\cline { 2 - 3 } $\begin{array}{c}\text { Day of } \\
\text { gestation }\end{array}$ & Allantoic fluid & Amniotic fluid \\
\hline 32 & $<40$ & $<40$ \\
41 & 40 & $<40$ \\
52 & 1200 & 120 \\
68 & 7000 & 19000 \\
\hline
\end{tabular}

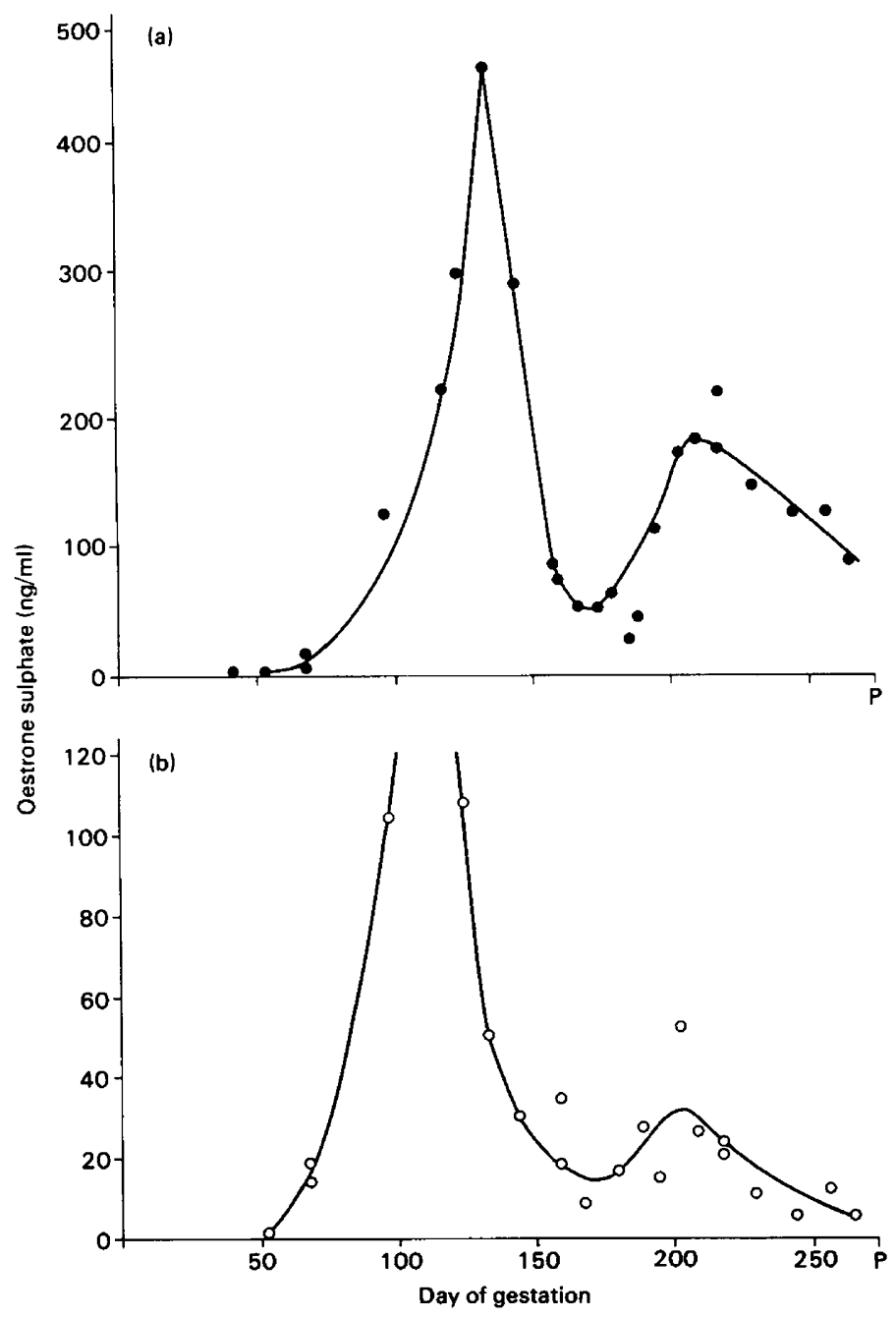

Text-fig. 1. The changes in concentration of oestrone sulphate in the (a) allantoic and (b) amniotic fluids of the cow throughout pregnancy. $P=$ the time of parturition. Values are given as the oestrone equivalent and the curves are fitted by eye. 
Allantoic and amniotic fluids

Oestrone sulphate. In allantoic fluid oestrone sulphate was first present in measurable amounts between Days 41 and 52 (Table 1). A peak of $475 \mathrm{ng} / \mathrm{ml}$ was reached around Day 132 and this was followed by a sharp drop in concentration to a nadir around Day 170. There appeared to be a second smaller rise and decline (Text-fig. la).

In amniotic fluid oestrone sulphate was first detected at Day 52 (Table 1). Concentrations then rose rapidly to reach a peak of about $200 \mathrm{ng} / \mathrm{ml}$ around Day 110 (Text-fig. lb).

Oestradiol sulphates. During the first half of gestation the changes in concentration of the oestradiol sulphates in allantoic fluid were similar to those observed for oestrone sulphate. The earliest sample analysed (Day 72) contained $600 \mathrm{pg} / \mathrm{ml}$ (compared with $14.8 \mathrm{ng}$ oestrone sulphate $/ \mathrm{ml})$ and the lowest detectable level $(45 \mathrm{pg} / \mathrm{ml})$ would probably have occurred around Day 50. The highest concentration $(15.8 \mathrm{ng} / \mathrm{ml})$ was found at the same time as the peak in oestrone sulphate (Day 132) but was 30-fold lower (Text-fig. 2a).

The earliest amniotic fluid sample analysed (Day 72) contained $100 \mathrm{pg}$ oestradiol sulphate/ $\mathrm{ml}$, considerably less than that in allantoic fluid. Concentrations later in pregnancy were variable (Text-fig. 2b).

Ratio of oestradiol-17a sulphate to oestradiol-17 $\beta$ sulphate. Oestradiol-17 $\alpha$ sulphate was present in higher concentration than oestradiol- $17 \beta$ sulphate in all of the samples analysed (Table 2) and the ratio in amniotic fluid was considerably higher than that in allantoic fluid (means of 50.2 and 7.2 respectively).

Oestrone and oestradiol. The concentrations of the unconjugated oestrogens were very low relative to those of the corresponding conjugated oestrogens (Table 3), with few exceptions being much less than $3 \%$ of the conjugated oestrogen concentrations.

\section{Maternal jugular venous plasma}

Oestrone sulphate. Oestrone sulphate was readily detectable in the earliest sample analysed (Day 72) and the level rose fairly sharply until Day 147, then remained elevated (Table 3).

Oestrone. Oestrone was not measurable until Day 117 and in general the changes parallelled those for oestrone sulphate but at about a 30 -fold lower concentration (Table 3).

Oestradiol sulphates. Oestradiol sulphate was first detected at Day 97 (Table 3). A gradual rise occurred over Days 97-177 to reach a concentration of about $1 \mathrm{ng} / \mathrm{ml}$, but considerable fluctuations were then found between Days 177 and 270. Such differences may be due to

Table 2. The relative concentrations of oestradiol-17 $\beta$ sulphate and oestradiol-17 $\alpha$ sulphate in allantoic and in amniotic fluids of individual cows

\begin{tabular}{lccc}
\hline $\begin{array}{c}\text { Day of } \\
\text { gestation }\end{array}$ & $\begin{array}{c}\text { Oestradiol-17 } \\
\text { sulphate } \\
(\mathrm{ng} / \mathrm{ml})\end{array}$ & $\begin{array}{c}\text { Oestradiol-17a } \\
\text { sulphate } \\
(\mathrm{ng} / \mathrm{ml})\end{array}$ & $\begin{array}{c}\text { Ratio } \\
17 \alpha: 17 \beta \\
\text { sulphate }\end{array}$ \\
\hline Allantoic fluid & & & \\
132 & 5.4 & 30.0 & 5.6 \\
162 & 2.6 & 3.9 & 1.5 \\
192 & 0.5 & 8.9 & 15.3 \\
222 & 3.6 & 24.0 & 6.7 \\
250 & 1.8 & 12.0 & 6.7 \\
& & & \\
Amniotic fluid & & & \\
132 & 0.75 & 15.0 & 20.0 \\
162 & 0.9 & 60.0 & 67.0 \\
192 & 0.3 & 30.0 & 100.0 \\
222 & 0.45 & 18.0 & 40.0 \\
250 & 0.15 & 3.6 & 24.0 \\
\hline
\end{tabular}




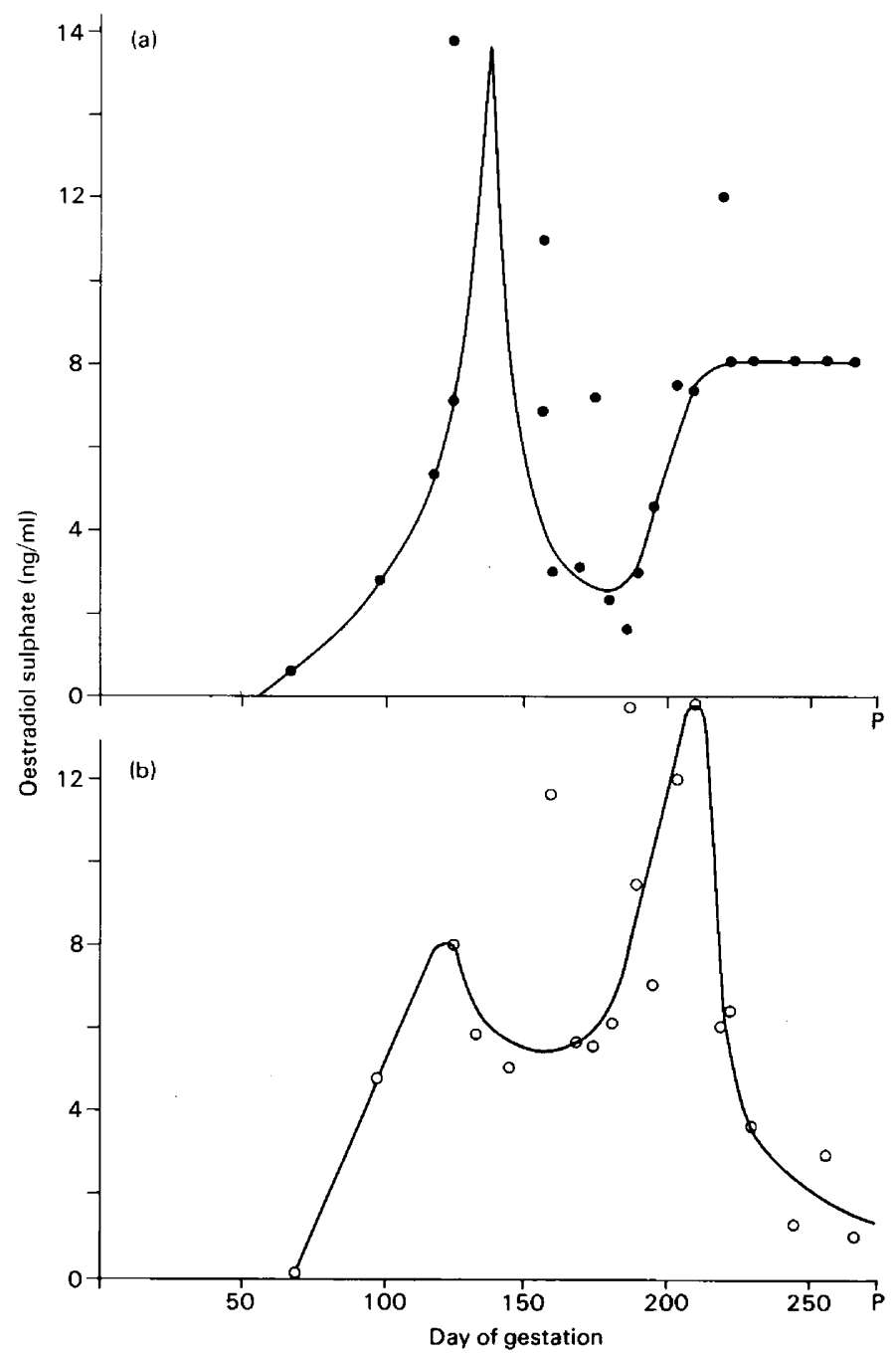

Text-fig. 2. The changes in concentration of the oestradiol sulphates $(-17 \alpha+-17 \beta)$ in the (a) allantoic and (b) amniotic fluids of the cow throughout pregnancy. $P=$ the time of parturition. Values are given as the oestradiol equivalent and the curves are fitted by eye.

individual variation during this period or two populations may be represented, one with a high level and one with a low level of oestradiol sulphate.

Oestradiols. Oestradiol was measurable from Day 97 and with one or two individual deviations a fairly steady concentration around $75 \mathrm{pg} / \mathrm{ml}$ was maintained until Day 261 .

\section{Effect of fetal sex on the unconjugated and sulpho-conjugated oestrogen concentration}

No difference in oestrogen concentration in any of the fetal or maternal fluids could be attributed to the sex of the fetus. Oestrogens were produced by the conceptus of both sexes early in pregnancy. Nevertheless, quantitative differences which are not apparent in this study, because of the relatively small numbers of samples analysed at any one stage of pregnancy, may be present. 
Table 3. The concentration $(\mathrm{pg} / \mathrm{ml})$ of unconjugated oestrogens in bovine fetal fluids, and of unconjugated and sulpho-conjugated oestrogens in maternal plasma, throughout pregnancy

\begin{tabular}{|c|c|c|c|c|c|c|c|c|}
\hline \multirow[b]{2}{*}{$\begin{array}{l}\text { Day of } \\
\text { gestation }\end{array}$} & \multicolumn{2}{|c|}{ Allantoic fluid } & \multicolumn{2}{|c|}{ Amniotic fluid } & \multicolumn{4}{|c|}{ Maternal plasma } \\
\hline & Oestrone & Oestradiols & Oestrone & Oestradiols & Oestrone & Oestradiols & $\begin{array}{l}\text { Oestrone } \\
\text { sulphate* }\end{array}$ & $\begin{array}{l}\text { Oestradiol } \\
\text { sulphatest }\end{array}$ \\
\hline 72 & 168 & $<40$ & $<40$ & $<40$ & $<40$ & $<40$ & 82 & $<40$ \\
\hline 97 & 392 & $<40$ & 786 & $<40$ & $<40$. & 136 & 260 & 68 \\
\hline 117 & 72 & $<40$ & - & $<40$ & 66 & $<40$ & 980 & 88 \\
\hline 123 & 66 & $<40$ & 160 & $<40$ & - & - & - & - \\
\hline 132 & 144 & $<40$ & 200 & $<40$ & 94 & 176 & 1520 & 228 \\
\hline 147 & 144 & $<40$ & 40 & $<40$ & 144 & 74 & 2610 & 358 \\
\hline 162 & $<40$ & $<40$ & 48 & 64 & 106 & 126 & 2500 & 388 \\
\hline 162 & $<40$ & $<40$ & 92 & 93 & 80 & 108 & 2290 & 700 \\
\hline 171 & 2670 & 450 & 54 & $<40$ & 26 & $<40$ & 1190 & 400 \\
\hline 177 & 1600 & 184 & - & - & 266 & 76 & 3130 & 1140 \\
\hline 183 & 160 & $<40$ & 214 & 80 & 84 & 74 & 2820 & 1260 \\
\hline 189 & $<40$ & $<40$ & 400 & 293 & 54 & 90 & 1910 & 900 \\
\hline 192. & $<40$ & $<40$ & $<40$ & 65 & 174 & 62 & 2868 & 228 \\
\hline 198 & $<40$ & $<40$ & 120 & 80 & 214 & 220 & 2720 & 1260 \\
\hline 207 & $<40$ & $<40$ & 692 & 272 & 200 & 94 & 2220 & 500 \\
\hline 213 & $<40$ & 52 & 306 & 400 & 120 & 86 & 2740 & 1200 \\
\hline 222 & 84 & 68 & 426 & 200 & 134 & 68 & 3667 & 368 \\
\hline 225 & $<40$ & $<40$ & 2666 & 360 & 62 & 68 & 2970 & 1280 \\
\hline 234 & 1334 & 144 & 1600 & 293 & 54 & 70 & 2330 & 860 \\
\hline 250 & $<40$ & $<40$ & 94 & 43 & 94 & 81 & 2875 & 388 \\
\hline 261 & $<40$ & $<40$ & 1866 & 200 & 134 & 98 & 3570 & 1140 \\
\hline 270 & $<40$ & $<40$ & 496 & 91 & 186 & 896 & 4038 & 488 \\
\hline
\end{tabular}

* As the unconjugated oestrone equivalent.

+ As the unconjugated oestradiol equivalent.

\section{Discussion}

The data show that, within the limits of the sensitivity of the assay and of the number of animals sampled, oestrogens were present in the fetal fluids of the cow earlier than Day 52. The principal oestrogen was oestrone sulphate which attained the very high concentration of $475 \mathrm{ng} / \mathrm{ml}$ in allantoic fluid around Day 132.

The peak in the concentration of oestrone sulphate in amniotic fluid at Day 110 precedes that in the allantoic fluid by some 23 days although the reverse has been found for the ewe (Carnegie \& Robertson, 1978). The initial rise in oestrone sulphate concentrations can be attributed to the increase in the mass of the placental tissue, membranes and/or fetus. At present the source of the oestrogens is not known. Gadsby, Burton, Heap \& Perry (1976) failed to obtain evidence for oestrogen synthesis in vitro by either tissues or membranes of the early bovine or ovine conceptus although Attal (1969) had detected oestrogen precursors, androstenedione and testosterone, in the testes of fetal lambs by Day 30 of intrauterine life.

No explanation can be offered for the precipitous drop in concentration of oestrone sulphate observed in bovine fetal fluids between Days 132 and 170 when the mass of the conceptus is still increasing. There appears to be a marked depression of oestrogen synthesis since there is no evidence for a diversion of oestrogens into other fluids at this time. It is possible that the second peak of oestrone sulphate which is observed in the allantoic fluid arises from a new source. This pattern of oestrone sulphate concentrations in the allantoic fluid of the cow, i.e. a sharp peak relatively early in pregnancy followed by a second rise commencing around mid-pregnancy, and a subsequent decline towards late pregnancy, is similar to that found in the allantoic fluid of the ewe (Carnegie \& Robertson, 1978) and in the peripheral plasma of the pregnant sow (Robertson 
\& King, 1974; Robertson et al., 1978) although the initial peaks occur at different times of gestation (Day 135 for the cow, 45 for the ewe and 30 for the sow). In contrast to the pattern observed in the maternal peripheral plasma, there is no evidence for an increase in oestrone sulphate levels in samples of allantoic and amniotic fluid obtained during late gestation. A similar observation has been reported for the ewe (Carnegie \& Robertson, 1978).

This drop in the concentration of the oestrogen sulpho-conjugates late in pregnancy is in keeping with an observed fall in the concentration of the unconjugated oestrogens in the blood of fetal calves during the 8th month (Challis et al., 1974) and of the sulpho-conjugates in fetal ovine blood (Wong, Cox, Durrie \& Thorburn, 1972; Findlay \& Seamark, 1973). Findlay \& Seamark (1973) also found a rise immediately before parturition.

When representative samples of amniotic and allantoic fluids were analysed for oestradiol$17 \alpha$ sulphate and oestradiol- $17 \beta$ sulphate it was found that their ratio was relatively constant for each fluid but was higher in amniotic fluid. Since the samples tested covered the period from Day 132 to 250 the predominance of oestradiol-17a sulphate in the amniotic fluid at this time is indicative of fetal metabolism. The unconjugated oestrogens present in the fetal fluids at relatively low concentrations generally did not show any recognizable pattern and may be artefacts arising from a low degree of solvolysis of the sulpho-conjugates.

In the maternal blood the concentration of unconjugated oestrogens was low throughout pregnancy. The sulpho-conjugated oestrogens were measurable before Day 72 and the high concentration of oestrone sulphate relative to that for oestrone, oestradiol and the oestradiol sulphates present from Day 132 onwards is in keeping with the finding of Tsang, Hackett \& Turner (1975) that at parturition oestrone sulphate was the major oestrogen in the plasma of the pregnant cow. Differences in the concentrations of unconjugated oestrogens in fetal blood have been reported for female and male fetuses, with females having the higher concentration (Challis et al., 1974). It was not possible to confirm this finding from the limited data available.

Comparison of the present data with studies in the sow, in which oestrogen synthesis by the conceptus has been demonstrated in vitro as early as Day 12 (Perry, Heap \& Amoroso, 1973) and oestrogens of embryonic origin have been detected in the maternal peripheral plasma by Day 17 (Robertson \& King, 1974; Robertson et al., 1978), suggests that the first appearance of oestrogens in the conceptus of the cow occurs much later in relation to the start of attachment to the maternal uterus. The cow may therefore be more like the ewe in which evidence for oestrogen synthesis by the conceptus was first found around Day 31 (Carnegie \& Robertson, 1978). The failure to obtain evidence for oestrogen synthesis in vitro by tissues and membranes of the early bovine conceptus (Gadsby et al., 1976), and the present data, tend to argue against oestrogens of embryonic origin being involved as an antiluteolytic or luteotrophic factor in the cow, but the role of these oestrogens, particularly the sulpho-conjugates, during early pregnancy is still obscure.

We wish to acknowledge the help of B. Atkinson in obtaining these samples and the skilled technical assistance of R. Durnford who carried out the analyses. This paper is No. 759 of the Animal Research Institute.

\section{References}

Abraham, G., Tulchinsky, D. \& Korenman, S. (1970) Chromatographic purification of estradiol-17 $\beta$ for use in radioligand assay. Biochem. Med. 3, 365-368.

Attal, J. (1969) Levels of testosterone, androstenedione, estrone and estradiol- $17 \beta$ in the testes of fetal sheep. Endocrinology 85, 280-289.

Carnegie, J.A. \& Robertson, H.A. (1978) Conjugated and unconjugated estrogens in fetal and maternal fluids of the pregnant ewe: a possible role for estrone sulfate during early pregnancy. Biol. Reprod. 19, 202-211.

Challis, J.R.G., Kim, C.K., Naftolin, F., Judd, H.L., Yen, S.S.C. \& Benirschke, K. (1974) The concentrations of androgens, oestrogens, progesterone and lutein- 
izing hormone in the serum of foetal calves throughout the course of gestation. J. Endocr. 60, 107-115.

Findlay, J.L. \& Seamark, R.F. (1973) The occurrence and metabolism of oestrogens in the sheep foetus and placenta. In The Endocrinology of Pregnancy and Partuition-Experimental Studies in the Sheep, pp. 54-74. Ed. C. G. Pierrepoint. Alpha Omega Alpha, Cardiff.

Gadsby, J.E., Burton, R.D., Heap, R.B. \& Perry, J.S. (1976) Steroid metabolism and synthesis in early embryonic tissue of pig, sheep and cow. J. Endocr. 71, 45p.

Gorski, R.A. (1971) Gonadal hormones and perinatal development of neuroendocrine function. In Frontiers of Neuroendocrinology, pp. 278-290. Eds L. Martini \& W. F. Ganong. Oxford University Press, New York.

Jost, A. (1969) The extent of foetal endocrine autonomy. In Foetal Autonomy, pp. 79-89. Eds G. E. W. Wolstenholme \& M. O'Connor. Churchill, London.

Jost, A. (1970) Hormonal factors in the sex differentiation of the mammalian foetus. Phil. Trans. $R$. Soc. Ser. B 259, 119-131.

Liggins, G.C. (1969) The foetal role in the initiation of parturition in the ewe. In Foetal Autonomy, pp. 218231. Eds G. E. W. Wolstenholme \& M. O'Connor. Churchill, London.

Loriaux, D.L., Ruder, H.J. \& Lipsett, M.B. (1971) The measurement of estrone sulfate in plasma. Steroids 18, 463-472.

Perry, J.S., Heap, R.B. \& Amoroso, E.C. (1973) Steroid hormone production by pig blastocysts. Nature, Lond. 245, 45-47.
Roberts, S.J. (1956) Veterinary Obstetrics and Genital Diseases. Edward Bros., Ann Arbor.

Robertson, H.A. \& King, G.J. (1974) Plasma concentrations of progesterone, oestrone, oestradiol-17 $\beta$ and of oestrone sulphate in the pig at implantation, during pregnancy and at parturition. J. Reprod. Fert. 40, 133-141.

Robertson, H.A. \& King, G.J. (1975) Estrogens and placental attachment in the cow. J. Anim. Sci. 41, 377.

Robertson, H.A., Smeaton, T. \& Durnford, R. (1972) A method for the extraction, separation and estimation of unconjugated estradiol, estradiol-17 $\alpha$ and estradiol-17 $\beta$ in plasma. Steroids 20, 651-667.

Robertson, H.A., King, G.J. \& Carnegie, J.A. (1976) Oestrone sulphate and embryonic attachment in the cow, ewe and sow. Proc. 8th Int. Congr. Anim. Reprod. \& A. I., Krakow, Vol. 1, Abstr. 214

Robertson, H.A., King, G.J. \& Dyck, G.W. (1978) The appearance of oestrone sulphate in the plasma of the sow early in pregnancy. $J$. Reprod. Fert. 52, 337338.

Tsang, C.P.W., Hackett, A.J. \& Turner, E.M. (1975) Plasma levels of estrone sulfate, estrone and estradiol-17 $\beta$ in the cow around parturition. Can. $J$. Anim. Sci. 55, 509-512.

Wong, M.S.F., Cox, R.I., Currie, W.B. \& Thorburn, G.D. (1972) Changes of oestrogen sulpho-conjugates in the foetal plasma of sheep and goats during late gestation. In Proc. 15th Ann. Meeting Endocrine Soc. Australia, Sydney, Vol. 15, 8, Abstr.

Received 29 August 1978 